Clinical Images

\section{Oral submucous fibrosis}

\section{Image in allergy}

A 34 year old male patient presented with complaints of burning sensation in the mouth for 2 years and progressive difficulty in opening the mouth since 1 year. He had been chewing areca nut along with tobacco for past 5 years. On examination the patient had trismus with mouth opening of only $2.2 \mathrm{~cm}$ and poor oral hygiene. The oral mucosa was pale with multiple thickenings across the palatal and buccal mucosa suggestive of fibrous bands (Panel A). The patient was treated with submucosal injections of triamcinolone and hyaluronidase every week for 6 weeks and was advised to stop chewing tobacco and areca nut. His symptoms gradually improved and the mouth opening improved to $3 \mathrm{~cm}$ at the end of 6 weeks. There has been no progression in the symptoms at 3 months of follow up. Oral submucous fibrosis (OSF) is a chronic, progressive, insidious, irreversible disease of the oral cavity characterized by fibrotic change and severe burning sensation with restricted opening of the mouth. It was first described by Schwartz, which he called "atrophia idiopathica mucosae oris." Later in 1953, Joshi coined the term submucous fibrosis (Figure 1). The etiology is linked to chewing of areca nut with or without tobacco with a genetic, immunologic or nutritional predisposition to the disease. It largely affects people of South East Asia and immigrant population from this area in other parts of the world. The pathogenisis is still not fully understood, it is seen that in OSF the oral fibroblasts are phenotypically altered, possibly due to some chemicals in the areca nut. These altered fibroblasts produce lower amounts of collagenolytic enzyme matrix metalloproteinases and increased amount of tissue inhibitors of matrix metalloproteinases resulting in the formation of thick collagen bands. There is no definite treatment and various modalities like local injection of steroids, nutritional supplements and even stem cell therapy have been tried, out of these only local injections of triamcinolone and hyaluronidase have proven to be of some benefit. Severe trismus needs surgical intervention either by lasers or surgical removal of the fibres followed by grafting. It is a premalignant condition and long term follow up of the patient is warranted. The prognosis is poor as most of the patients have persistent symptoms.

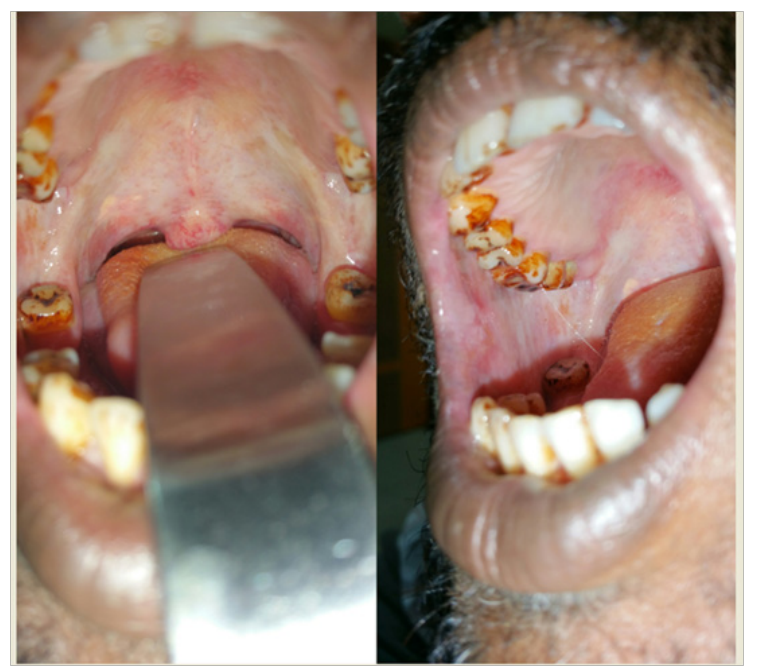

Figure I Thick white fibrous band across the soft palate and buccal mucosa in patient with oral submucous fibrosis.
Volume 10 Issue $3-2018$

\section{Satvinder Singh Bakshi}

Department of ENT and Head \& Neck Surgery, Mahatma Gandhi Medical College and Research Institute, India

Correspondence: Satvinder Singh Bakshi, Associate Professor of ENT, Department of ENT and Head \& Neck Surgery, Mahatma Gandhi Medical College and Research Institute, Pillaiyarkuppam, Pondicherry 607402, India, Tel 9698420998, Email saty.bakshi@gmail.com

Received: November 01, 2017 | Published: May 242018

\section{Acknowledgments}

None.

\section{Financial disclosure}

No funding was obtained and there are no financial disclosures.

\section{Conflict of interest}

None. 